\title{
Proceeding
}

Supplementary Issue: Summer Conferences of Sports Science. First International Conference in Iraq on Sport for Peace, 4 April 2019. Baghdad Science Institute, Baghdad, Iraq.

\section{Specificity of physical development and physical preparation of schoolchildren of Orenburg and Aktobe cities}

\author{
S. KUBIYEVA 1 , T. BOTAGARIEV ${ }^{1}$, A. AKHMETOVA ${ }^{1}$, P. TISSEN ${ }^{2}$, E. ZHETIMEKOV ${ }^{2}$, M. BOBYREVA ${ }^{3}$, \\ N. MAMBETOV ${ }^{3}$, A. ARALBAEV 4
}

${ }^{1}$ Aktobe Regional State University named after K. Zhubanova, Aktobe, Republic of Kazakhstan

${ }^{2}$ Orenburg State Pedagogical University, Orenburg, Russia

${ }^{3}$ West Kazakhstan State Medical University named after M. Ospanov, Aktobe, Republic of Kazakhstan

${ }^{4}$ Atyrau State University named after H. Dosmukhamedov, Atyrau, Republic of Kazakhstan

\begin{abstract}
The article describes the opinion of teachers of physical culture of the cities of Orenburg and Aktobe on the factors that determine the level of physical fitness and physical development of schoolchildren. Relatively reduced quantitative values of their teachers of Aktobe are shown. Among the factors determining the level of physical fitness and physical development of schoolchildren, teachers identified the material base, lack of organization of special medical groups, inconsistency of physical development with the passport age, undue development of independent work programs, homework to improve schoolchildren's physical fitness, low motivation and indifference of parents. The lag of Aktobe schoolchildren from their peers from Orenburg in the development of speed, speed-strength qualities, body length, vital index, arterial pressure was revealed. Ways of improving the physical fitness of schoolchildren are presented, namely, recommendations on the development of independent work programs, homework assignments, work with parents, a set of exercises for the development of lagging physical qualities, respiratory muscles. The contribution of the article to world science are: data on the physical development and physical fitness of schoolchildren of Orenburg and Aktobe compared with similar data from the 90s of the last century; information about the opinion of teachers of physical culture on the factors that determine the level of physical fitness and physical development of schoolchildren; recommendations to teachers of physical culture to optimize the physical training of schoolchildren. Keywords: Factors; Physical development; Physical; Fitness; Schoolchildren; Orenburg; Aktobe; Theoretical aspects; Ways and improvement.
\end{abstract}

Cite this article as:

Kubiyeva, S., Botagariev, T., Akhmetova, A., Tissen, P., Zhetimekov, E., Bobyreva, M., Mambetov, N., \& Aralbaev, A. (2019). Specificity of physical development and physical preparation of schoolchildren of Orenburg and Aktobe cities. Journal of Human Sport and Exercise, 14(5proc), S2037-S2051. doi:https://doi.org/10.14198/ihse.2019.14.Proc5.26

Corresponding author. Aktobe Regional State University named after K. Zhubanova, Aktobe, Republic of Kazakhstan.

E-mail: samyshevez.kaz2@gmail.com

Supplementary Issue: Summer Conferences of Sports Science. First International Conference in Iraq on Sport for Peace, 4 April 2019. Baghdad Science Institute, Baghdad, Iraq.

JOURNAL OF HUMAN SPORT \& EXERCISE ISSN 1988-5202

(c) Faculty of Education. University of Alicante

doi:10.14198/jhse.2019.14.Proc5.26 


\section{INTRODUCTION}

At the present stage in the Republic of Kazakhstan, as well as throughout the world, there are processes of reforming education. This is accompanied by increased demands on the mental, physical performance of children. In turn, as expert's note (Kainov, 2004), this leads to deterioration in the health, physical fitness, and physical development of children. These facts determine the need to take into account the peculiarities of physical fitness and physical development of schoolchildren when building the process of their physical education. The foregoing determines the relevance of the study. The choice of the research topic is determined by the following reasons. As you know, one of the main signs of physical perfection of schoolchildren is indicators of their physical fitness and physical development. According to the data of experts (Dolzhikova, 2011; Levushkin, 2005), their indicators tend to worsen. Modern physical education programs for general education schools do not take into account the level of preparedness of students, their physical condition. This does not allow differentiating to build the process of physical education of students. Such scientist as (Kainov ,2004), (Dolzhikova,2011), Lebed paid attention to this problem of research (1997), (Burlykov, 2006), (Kuralev, 2004), (Gorobiy, 2007), (Puzyr', 2006), (Schetinina,2014), (Zeighami \& Bahmaei,2016), (Novikasari, 2017) and others. The contribution of this article to world science is the following. First, comparative data are presented on the physical fitness and physical development of schoolchildren of Orenburg and Aktobe. Secondly, the characteristics of the factors determining their level on the basis of the opinion of physical culture teachers are given. Thirdly, directions and the maintenance of means, methods, and forms of the organization of improvement of physical training of school students are developed. The practical significance of this work is as follows. The results can be used in the practice of physical education teachers in the following areas: in justifying the factors that determine the level of physical fitness and physical development of schoolchildren; when taking into account data on the level of physical fitness and physical development of schoolchildren of Aktobe and Orenburg; adoption of recommended means, methods, forms of organization of physical training of schoolchildren. The purpose of the study is to substantiate the methodological recommendations on the physical preparation of schoolchildren in Orenburg and Aktobe based on the use of data on their level of physical fitness and physical development. Research objectives. 1. To determine the opinion of physical culture teachers of Aktobe and Orenburg on the factors those determine the level of physical development and physical fitness of schoolchildren. 2. To study the level of physical fitness and physical development of schoolchildren of Aktobe and Orenburg. 3. Develop ways to optimize the physical training of schoolchildren of Aktobe and Orenburg.

\section{Literature review}

An analysis of literature has shown that the research of scientists on various aspects of the relationship between physical fitness and physical development of students can be grouped in the following areas. Differentiated assessment of physical fitness of students. In this area, experts recommend the following: a) "... as a methodological feature of a differentiated assessment of physical fitness, set anthropometric data that determine the level of physical development for each age group, as well as constitutional body types ..." (Kainov, 2004); b) "... At the age of 14 years, boys and girls with medium and low levels of physical fitness according to test data, it is advisable to change the direction and content of physical education, as well as assess the level of physical fitness" (Dolzhikova, 2011); c) "... Evaluation of the parameters of physical fitness of schoolchildren living in the industrial pollution zone can be carried out using the "Jurofit" tests" (Lebed', 1997). Physical fitness and physical development of schoolchildren. Experts consider the following aspects: a) "... The leading factor in the variability of indicators of physical development and physical fitness of students at 7-10 years is the passport age, at 11-14 years old - the level of biological maturation of the body, at the age of 15-17 years is a body type ..." (Burlykov, 2006); b) "... the best performance in motor tests: a long jump from the spot, body raising, flexibility, hanging on bent arms, running 10-20 meters from the course, 
running 30 meters, have children of 6-8 years of muscular type constitution" (Kuraleva, 2004); c) "... in the period from 1993 to 2003 schoolchildren of Ulyanovsk showed a tendency to decrease in the indicators of children's physical development, indicating the termination of acceleration processes" (Levushkin, 2005); d) "... boys and girls of Teleut have low indicators of body length, leg length in comparison with Russian schoolchildren; the body of Teleut boys and girls surpasses the peers of the Russian nationality in terms of overall aerobic endurance and coordination." (Makarova, 2001). Management of physical fitness of schoolchildren. Here, experts offer the following recommendations: a) "... The basis of the choice of means of technology management of physical fitness of high school students put correlation analysis, which revealed a positive relationship between the values of testing individual physical qualities with the level of physical fitness ..." (Gorobiy, 2007); b) "... The main factors that have a negative impact on the effectiveness of physical education in educational institutions of Moscow are: lack of material and technical support, control and analysis of students' health status; the inconsistency of the content of educational material features involved, low involvement of children in the form of physical exercise, low efficiency of management of physical education. ... " (Puzyr', 2006). Methods of physical training of students. Here, experts highlight the following aspects: a) "... The technology of development of physical abilities includes exercises for the development of physical abilities; for the section of the national-regional component; performed in physical fitness and physical fitness; used in sectional work; on independent physical training of students." (Feoktisov, 2010); b) "... Technology of differentiated physical education of schoolgirls on the basis of taking into account the features of the integral indicators of their physical condition includes determining the level of physical development, physical fitness" (Bortsova, 2006). Researches of foreign scientists are devoted to the consideration of the following problems. The relationship of physical activity with physical fitness and physical development of schoolchildren. Experts suggest the following results of their research: a) "... the change in the training impulse positively correlates with the change in the vital capacity" (Luo et al, 2018); b) "... cardiorespiratory readiness and the results of the long jump from the spot are inversely related to the risk factors of cardiovascular diseases ..." (Delgado-Floody et al 2019); c) "... There is a bi-directional synergistic relationship between body weight and motor skills." (Greier \& Drenowatz, 2018). d) "... The body mass index is positively associated with high blood pressure" (Benite-Ribeiro et al, 2016); e) "... levels of height, weight, body mass index and chest circumference were clearly increased in 2010 compared with these levels in 1985, especially in the age group 9-13 years old." (Zhi et al, 2015). Physical fitness and physical activity of schoolchildren. In this area, experts suggest the following results: a) "... in the process of physical education, the daily physical activity significantly increased, and the static component decreased." (Mooses et al, 2017); b) "... perceived competence and pleasure predicted physical activity for boys"(Zhang et al, 2015); c) "... levels of physical activity in children in pre-pubertal age may be associated with the acquisition of motor management skills to a greater extent than with the acquisition of physical fitness." (Haynes et al, 2017); d) "... Regardless of gender, children with low motor competence had less perceived competence, physical activity and cardiorespiratory fitness." (Gu et al, 2017). Physical training and student performance. Specialists offer the following recommendations: a) "... Physical activity at school based on a curriculum can improve the performance and psychological health of children, especially girls." (Kall et al, 2015); b) "... In 31 cases, a positive relationship was found between performance and the cardiorespiratory system, in 6 cases - with muscular strength, in 3 cases - with flexibility and 7th - a positive connection between clustering the components of physical fitness and performance" (Santana et al, 2017); c) "... In 10 of 16 cases, a positive relationship was found between self-assessment of physical activity and performance" (Marques et al, 2018). Assessment of physical fitness of schoolchildren. The specialists offer the following recommendations: "... the introduction of the book on the control of physical fitness for students of the 5th grade of primary school allows you to control and improve the physical form of students ..." (Abdullah \& Nandiyanto, 2017). 


\section{MATERIALS AND METHODS}

The study was conducted at the bases of secondary schools of Orenburg (No. 20, 25, 35, 45) and Aktobe (No. 27,25,23,3,) with 7th grade students and physical education teachers during 2017-2018, 2018-2019 school years in three stages. At the first stage (September - October 2017), the scientific and methodological literature was studied; the scientific research apparatus was developed. The method of analysis of scientific and methodical literature was used. At the second stage (2018-2019 academic year), the second and third tasks of our study were solved. To determine the views of teachers was developed questionnaire (Feresin \& Močinić, 2017). The questionnaire included questions related to the material base, special medical groups, physical development and physical fitness of schoolchildren, the orientation of physical education lessons, the use of documents in developing work programs, homework assignments to improve physical fitness, students' interest in lessons, extracurricular activities, reasons hampering physical fitness, the use of the third lesson of physical culture, the participation of parents in physical education of children. The method of questionnaire survey was used (Zheleznyak \& Petrov, 2002). The following indicators were used to determine the level of physical development: lung capacity, chest circumference (in pause, inhale and exhale), hand dynamometry, blood pressure, heart rate, body length, body weight. The method of anthropometric measurements and determination of the functional state of the organism was used (Landa, 2006). The following tests were used to determine the level of physical fitness: $100 \mathrm{~m}(\mathrm{~s}), 1000 \mathrm{~m}$ (min, s), long jump (cm), pulling up on a high crossbar (young man) (number of times), pulling up on low crossbar (girls) (number of times), throwing the ball (m), cross-country skiing for $2 \mathrm{~km}$ (min, $\mathrm{s}$ ) (Physical education: Training program. For students in grades 5-9 of secondary school, 2013). The test method was used (Zheleznyak \& Petrov, 2002). For statistical processing of results, the arithmetic average value $(\bar{X})$, standard deviation $(S)$, arithmetic average error (m), Student's t-criteria, probability of error in the table of Student coefficient (Zheleznyak \& Petrov, 2002) were used. A total of 200 boys (100 people from Orenburg and 100 people from Aktobe) and 200 girls (100 people from Orenburg and 100 people from Aktobe) were accepted in the study. Also, 100 physical education teachers (50 people from Orenburg and 50 people from Aktobe) took part in the questionnaire.

\section{RESULTS}

Table 1 presents the results of the questionnaire survey to identify the views of teachers of physical education in Orenburg and Aktobe on the factors determining the level of physical development and physical fitness of schoolchildren.

Table 1. Opinion of physical education teachers of Orenburg and Aktobe on the factors determining the level of physical development and physical fitness of schoolchildren.

\begin{tabular}{|c|c|c|c|}
\hline \multirow{2}{*}{ No } & Question and possible answers & \multicolumn{2}{|c|}{+} \\
\cline { 3 - 4 } & $\begin{array}{c}\text { Orenburg } \\
\mathrm{n}=50\end{array}$ & $\begin{array}{c}\text { Aktobe } \\
\mathrm{n}=50\end{array}$ \\
\hline \multirow{4}{*}{1} & Are you satisfied with the material and educational and & \\
& methodological base of the school for conducting physical & & \\
& education classes? & 35,9 & 30,1 \\
& yes & 64,1 & 69,9 \\
\hline \multirow{2}{*}{2} & Do & & \\
& Does the inventory ensure the quality of the educational process in & & \\
& accordance with the requirements of the state standard? & 41.2 & 29,2 \\
\hline
\end{tabular}




\begin{tabular}{|c|c|c|c|}
\hline & no & 58,8 & 70,8 \\
\hline 3 & $\begin{array}{l}\text { Do you have specially organized special medical groups? } \\
\qquad \text { yes } \\
\text { no }\end{array}$ & $\begin{array}{l}18,7 \\
81,3\end{array}$ & $\begin{array}{l}10,5 \\
89,5\end{array}$ \\
\hline 4 & $\begin{array}{l}\text { Do you think that the physical development of schoolchildren } \\
\text { corresponds to their passport age? } \\
\text { yes } \\
\text { no }\end{array}$ & $\begin{array}{l}40 \\
60\end{array}$ & $\begin{array}{l}38,9 \\
61,1\end{array}$ \\
\hline 5 & $\begin{array}{l}\text { Do you consider physical (motor) readiness of schoolchildren to be } \\
\text { sufficient for active life activity? } \\
\text { yes } \\
\text { no }\end{array}$ & $\begin{array}{l}43,2 \\
56,8\end{array}$ & $\begin{array}{l}35,2 \\
64,8\end{array}$ \\
\hline 6 & $\begin{array}{l}\text { What percentage of students copes with the age standards of } \\
\text { physical fitness, presented in the program for physical culture? } \\
\text { Specify the approximate percentage in accordance with the stage of } \\
\text { training: } \\
\text { primary school (grades 1-3) - copes } \\
\text { cannot cope } \\
\text { elementary school (grades 3-6)- copes } \\
\text { cannot cope } \\
\text { middle school (grades } 6-9 \text { )- copes } \\
\text { cannot cope } \\
\text { Indicate \% of students who are } 100 \% \text { able to cope with standards. } \\
\text { primary school } \\
\text { elementary school } \\
\text { middle school }\end{array}$ & $\begin{array}{c}42 \\
58 \\
45,9 \\
54,1 \\
35,9 \\
64,1 \\
\\
10,9 \\
6,2 \\
6,2\end{array}$ & $\begin{array}{l}25,3 \\
74,7 \\
35,2 \\
64,8 \\
25,3 \\
74,7 \\
\\
8,5 \\
5,3 \\
4,8\end{array}$ \\
\hline 7 & $\begin{array}{l}\text { Indicate (tick) the primary focus of your lessons: } \\
\text { - training (providing an increase in the functionality of the body } \\
\text { directly in the classroom) } \\
\text { - educational (providing the formation of theoretical readiness for } \\
\text { self-study) }\end{array}$ & $\begin{array}{l}88 \\
12 \\
\end{array}$ & 78,8 \\
\hline 8 & $\begin{array}{l}\text { Do you carry out the educational process using a modified or } \\
\qquad \text { developed program (tick)? } \\
\text { - according to the program developed by me } \\
\text { - according to the modified program }\end{array}$ & $\begin{array}{c}5 \\
42\end{array}$ & 100 \\
\hline 9 & $\begin{array}{c}\text { Does your professional competence allow you to independently } \\
\text { develop a work program in physical culture in accordance with the } \\
\text { requirements of the state standard? } \\
\text { yes }\end{array}$ & 78,1 & 38,2 \\
\hline
\end{tabular}




\begin{tabular}{|c|c|c|c|}
\hline & no & 21,9 & 61,8 \\
\hline 10 & $\begin{array}{c}\text { In developing the work program, you relied on the following } \\
\text { documents (you can tick a few options): } \\
\text { - state educational standard } \\
\text { - Approximate program in physical culture (Russia) Program in } \\
\text { physical culture (Kazakhstan, Astana 2013), Model curriculum on } \\
\text { the subject "Physical culture" for grades } 5-9 \text { of the level of basic } \\
\text { secondary education with updated content } \\
\text { - A comprehensive program of physical education students } 1 \text { - } 11 \\
\text { classes } \\
\text { - The program of physical education students } 1 \text { - } 11 \text { classes, based } \\
\text { on one of the sports (basketball) } \\
\text { - Other programs }\end{array}$ & 81 & $\begin{array}{l}100 \\
100\end{array}$ \\
\hline 11 & $\begin{array}{l}\text { Does the content of the current program of physical education for } \\
\text { schoolchildren satisfy you? } \\
\text { yes } \\
\text { no }\end{array}$ & $\begin{array}{l}49,9 \\
50,1\end{array}$ & $\begin{array}{l}10,2 \\
89,2\end{array}$ \\
\hline 12 & $\begin{array}{c}\text { Do you have a system of homework in physical culture, aimed at } \\
\text { improving the indicators of physical development and physical } \\
\text { fitness of schoolchildren? } \\
\text { yes } \\
\text { no }\end{array}$ & $\begin{array}{l}43,3 \\
56,7\end{array}$ & $\begin{array}{l}33,3 \\
66,7\end{array}$ \\
\hline 13 & $\begin{array}{l}\text { Does the student have an interest in physical education classes? } \\
\qquad \text { yes } \\
\text { no }\end{array}$ & $\begin{array}{c}92 \\
8\end{array}$ & $\begin{array}{l}72,8 \\
27,2\end{array}$ \\
\hline 14 & $\begin{array}{c}\text { Are students interested in extra-curricular physical education } \\
\text { classes? } \\
\text { yes } \\
\text { no }\end{array}$ & $\begin{array}{c}96 \\
4\end{array}$ & $\begin{array}{l}89,6 \\
20,4\end{array}$ \\
\hline 15 & $\begin{array}{l}\text { Do physical education lessons affect the improvement of physical } \\
\text { development and physical fitness of schoolchildren? } \\
\text { yes } \\
\text { no }\end{array}$ & $\begin{array}{c}90,6 \\
9,4\end{array}$ & $\begin{array}{l}75,3 \\
24,7\end{array}$ \\
\hline 16 & $\begin{array}{l}\text { What hinders in your work the improvement of physical fitness of } \\
\text { schoolchildren? (underline necessary or add your own) } \\
\text { - weak material base } \\
\text { - unwillingness of students to engage in, their low motivation } \\
\text { - parental indifference } \\
\text { - own not knowledge of working methods }\end{array}$ & $\begin{array}{c}78 \\
50 \\
35 \\
1\end{array}$ & $\begin{array}{l}82,3 \\
56,3 \\
45,2 \\
8,4\end{array}$ \\
\hline 17 & $\begin{array}{l}\text { How is the third lesson in physical culture used (check the box next } \\
\text { to the judgment)? } \\
\text { - the variable part of the program approved at school is being } \\
\text { implemented }\end{array}$ & 28,1 & 85,3 \\
\hline
\end{tabular}




\begin{tabular}{|c|c|c|c|}
\hline & $\begin{array}{c}\text { - program material is distributed proportionally to sections } \\
\text { - includes material to improve students' physical fitness } \\
\text { - missing }\end{array}$ & $\begin{array}{r}71,8 \\
6 \\
1\end{array}$ & $\begin{array}{l}56,9 \\
15,2 \\
-\end{array}$ \\
\hline 18 & $\begin{array}{c}\text { Do parents participate in schoolchildren's physical education? } \\
\text { yes } \\
\text { always } \\
\text { not regular } \\
\text { no }\end{array}$ & $\begin{array}{l}12,5 \\
71,6 \\
6,4 \\
9,5\end{array}$ & $\begin{array}{c}10,2 \\
65,2 \\
5,6 \\
18,6\end{array}$ \\
\hline 19 & $\begin{array}{l}\text { Your suggestions for optimizing the physical development and } \\
\text { physical fitness of schoolchildren (list } 2 \text { - } 3 \text { of the most significant) } \\
\text { - organization of physical education lessons in the gym for one } \\
\text { class separately } \\
\text { - improvement of the material base } \\
\text { - the irrationality of the electronic journal } \\
\text { - development of a unified educational program } \\
\text { - improving the educational "status" of the lesson of physical culture }\end{array}$ & $\begin{array}{l}35,9 \\
45,8 \\
24,3 \\
18,8 \\
12,3\end{array}$ & $\begin{array}{l}25,2 \\
56,2 \\
28,2 \\
26,2 \\
56,2\end{array}$ \\
\hline
\end{tabular}

As can be seen from table 1 in many respects, the quantitative values of the views of teachers of physical culture in Aktobe are relatively lower than those of their colleagues from Orenburg. Thus, the material base does not satisfy physical culture teachers (69.9 versus $64.1 \%$ ). Therefore, most of them believe that the inventory does not ensure the quality of the educational process (70.8 vs. $58.8 \%$ ). In schools in both cities there are few organized medical groups (89.5 and 81.3\%). Most respondents believe that the physical development of schoolchildren does not correspond to their passport age (64.8\% and 56.8\%). Also, most respondents emphasize the lack of physical fitness of schoolchildren for sufficiently active life $(64.8 \%$ and $56.8 \%$ ). This, apparently, affects the fact that the prevailing part of schoolchildren, especially in secondary school, does not cope with the delivery of school standards for physical culture $(74.7$ and $64.1 \%)$. At $100 \%$, schoolchildren of primary classes do better with the delivery of standards (8.5 and $10.9 \%$ ). In the schools of Orenburg, physical education lessons have more training directions (88\%), and Aktobe has an educational orientation (78.8\%). In Aktobe schools, all teachers (100\%) work according to a single program (Physical education: Training program. For students in grades 5-9 of secondary school, 2013), and in Orenburg according to a developed program $-5 \%$ and to a modified program - $42 \%$. This is apparently connected with the fact that $78.1 \%$ of Orenburg teachers can independently develop a work program (against $38.2 \%$ from Aktobe). When developing a work program, $94 \%$ of Orenburg respondents rely on state standards, $81 \%$ on a comprehensive program, $22 \%$ on other programs; $100 \%$ - on the approximate program in physical culture. $100 \%$ of Aktobe teachers use the standard curriculum (Physical education: Training program. For students in grades 5-9 of secondary school, 2013) and the program on physical culture (The model curriculum in the subject "Physical Education" for grades 5-9 of the level of basic secondary education in the updated content, 2017). At the same time, $89.2 \%$ of Aktobe residents and $50.1 \%$ of Orenburg citizens do not satisfy the content of the current physical education program. The 66.7 and 56.7 respondents pay attention to the fact that the homework system does not improve the indicators of physical development and physical fitness of schoolchildren. At the same time, in both cities there is an interest of students in the lesson and extracurricular physical education classes $(72.8 ; 92 \%$ and $89.6 ; 96 \%)$. Therefore, most teachers point out the presence of the influence of physical education lessons on the improvement of physical development indicators and 
physical fitness of schoolchildren. Among the reasons preventing students from improving their physical fitness, respondents identified a weak material base ( 82.3 and $78 \%$ ), low motivation (56.3 and $50 \%$ ) and indifference of parents ( 45.2 and $35 \%$ ). The reliability of the latter fact is evidenced by the fact that 18.6 and $9.5 \%$ of parents do not participate in the physical education of their children. It is noteworthy that there is a low percentage of inclusion of material to improve the physical fitness of schoolchildren in the third lesson in physical culture (15.2 and 6\%). Among the proposals for optimizing the physical development and physical fitness of schoolchildren are the following. Organization of physical education lessons in the gym for one class separately (25.2 and $35.9 \%$ ), improvement of the material base (56.2 and $45.8 \%$ ), inefficiency of keeping an electronic journal (28.2 and 24.3\%), the development of a unified educational program (26.2 and $18.8 \%$ ), an increase in the educational "status" of a physical culture lesson (56.2 and 12.3\%). Table 2 presents the indicators of physical fitness of the young men of the 7th grade of the cities of Orenburg and Aktobe. An analysis of the results obtained revealed the following patterns. In the $60 \mathrm{~m}$ race, the young men of Orenburg were ahead of their peers from Aktobe: 10.08 seconds versus 10.4 seconds, a gain of 3.1 ( $p$ $<0.01$ ). The same tendency was noted in the long jump: the young men of Orenburg showed a result 18.85 $\mathrm{cm}$ higher than their peers from Aktobe $(p<0.01)$. But in the $1000 \mathrm{~m}$ race and throwing the ball, the young men of Aktobe showed relatively better results compared to schoolchildren from Orenburg. So, in the 1000 $\mathrm{m}$ race for $1.08 \mathrm{~s}(\mathrm{p}<0.01)$ and in throwing the ball for $1.2 \mathrm{~m}(\mathrm{p}>0.05)$. In pulling up on the crossbar and cross-country skiing $(2 \mathrm{~km})$, the results of the young men of Orenburg were relatively better. In the pull-up on the bar - by 3.1 times and cross-country skiing $(2 \mathrm{~km})$ - by $0.39 \mathrm{~min}$. $(\mathrm{p}<0.01)$.

Table 2. Indicators of physical fitness of boys 7 classes of Orenburg and Aktobe.

\begin{tabular}{|c|c|c|c|c|c|c|c|c|c|c|}
\hline \multirow{2}{*}{ No } & \multirow{2}{*}{ Indicators } & \multicolumn{3}{|c|}{$\begin{array}{c}\text { Orenburg } \\
n=100\end{array}$} & \multicolumn{3}{|c|}{$\begin{array}{l}\text { Aktobe } \\
n=100\end{array}$} & \multirow{2}{*}{ Growth } & \multirow[t]{2}{*}{$t$} & \multirow{2}{*}{$p$} \\
\hline & & $\overline{\mathrm{X}}$ & $S$ & $\mathrm{~m}$ & $\bar{X}$ & $S$ & $\mathrm{~m}$ & & & \\
\hline 1 & $60 \mathrm{~m}$ race, s & 10,08 & 0,44 & 0,06 & 10,4 & 0,6 & 0,08 & 3,1 & 3,2 & $<0,01$ \\
\hline 2 & $\begin{array}{l}\text { Long jump start, } \\
\text { sm }\end{array}$ & 334,25 & 46,6 & 0,59 & 315,4 & 41,1 & 5,81 & 2,7 & 2,14 & $<0,05$ \\
\hline 3 & $\begin{array}{c}1000 \mathrm{~m} \text { race, } \\
\mathrm{min} / \mathrm{s}\end{array}$ & 5,9 & 0,33 & 0,05 & 4,82 & 0,70 & 0,09 & 22,4 & 10,8 & $<0,01$ \\
\hline 4 & $\begin{array}{l}\text { Throwing the } \\
\text { ball, } m\end{array}$ & 25,3 & 3,78 & 0,53 & 26,5 & 4,67 & 0,66 & 4,7 & 1,42 & $>0,05$ \\
\hline 5 & $\begin{array}{l}\text { Pulling up on a } \\
\text { crossbeam } \\
\text { (number of } \\
\text { times) }\end{array}$ & 7,6 & 3,56 & 0,50 & 4,5 & 0,33 & 0,47 & 68,8 & 4,6 & $<0,01$ \\
\hline 6 & $\begin{array}{l}\text { Cross-country } \\
\text { skiing } \\
2 \mathrm{~km} \text { (min, s) }\end{array}$ & 14,6 & 0,51 & 0,07 & 14,99 & 0,63 & 0,08 & 2,6 & 3,9 & $<0,01$ \\
\hline
\end{tabular}

Table 3 presents the results of the study of the level of physical fitness of girls in grades 7 of Orenburg and Aktobe. 
Table 3. Indicators of physical fitness of girls of 7 classes of Orenburg and Aktobe.

\begin{tabular}{|c|c|c|c|c|c|c|c|c|c|c|}
\hline \multirow{2}{*}{ No } & \multirow{2}{*}{ Indicators } & \multicolumn{3}{|c|}{$\begin{array}{c}\text { Orenburg } \\
n=100\end{array}$} & \multicolumn{3}{|c|}{$\begin{array}{l}\text { Aktobe } \\
n=100\end{array}$} & \multirow[t]{2}{*}{ Growth } & \multirow[t]{2}{*}{$t$} & \multirow[t]{2}{*}{$p$} \\
\hline & & $\overline{\mathrm{X}}$ & $S$ & $\mathrm{~m}$ & $\bar{X}$ & $S$ & $\mathrm{~m}$ & & & \\
\hline 1 & $60 \mathrm{~m}$ race, $\mathrm{s}$ & 10,5 & 0,49 & 0,07 & 11,7 & 0,33 & 0,05 & 11,4 & 18 & $<0,01$ \\
\hline 2 & $\begin{array}{l}\text { Long jump } \\
\text { start, sm }\end{array}$ & 321 & 3,33 & 0,47 & 296,5 & 5,6 & 0,79 & 8,2 & 26,6 & $<0,01$ \\
\hline 3 & $\begin{array}{c}1000 \mathrm{~m} \text { race, } \\
\mathrm{min} / \mathrm{s}\end{array}$ & 4,9 & 0,35 & 0,05 & 6,21 & 0,24 & 0,03 & 26,7 & 21,8 & $<0,01$ \\
\hline 4 & $\begin{array}{l}\text { Throwing the } \\
\text { ball, } m\end{array}$ & 18,4 & 0,71 & 0,10 & 19,8 & 0,88 & 0,12 & 7,6 & 9,3 & $<0,01$ \\
\hline 5 & $\begin{array}{c}\text { Pulling up on a } \\
\text { crossbeam } \\
\text { (number of } \\
\text { times) }\end{array}$ & 17,0 & 0,49 & 0,07 & 14,5 & 0,07 & 0,51 & 17,5 & 28,2 & $<0,01$ \\
\hline 6 & $\begin{array}{l}\text { Cross-country } \\
\text { skiing } \\
2 \mathrm{~km} \text { (min, s) }\end{array}$ & 15,5 & 0,49 & 0,07 & 15,88 & 0,51 & 0,07 & 2,1 & 4,7 & $<0,01$ \\
\hline
\end{tabular}

As can be seen from table 3 , in the run at $60 \mathrm{~m}$, the long jump from the run, the $1000 \mathrm{~m}$ race the results of the girls from Orenburg were relatively better than their peers from Aktobe. So, in the $60 \mathrm{~m}$ race - for 1.2 seconds. ( $p<0.01)$, long jump with a take-off run - by $24.5 \mathrm{~cm}(p<0.01)$ and in a $1000 \mathrm{~m}$ race - by $1.31 \mathrm{sec}$. $(p<0.01)$. In throwing the ball, the girls of the city of Aktobe were relatively ahead of their peers from the city of Orenburg (by $1.4 \mathrm{~m}, \mathrm{p}<0.01$ ). The results of schoolgirls from Orenburg were relatively better in pulling on a low crossbar and cross-country skiing for $2 \mathrm{~km}$. So, in pulling up - by 2.5 times $(p<0.01)$ and cross-country skiing for $2 \mathrm{~km}-0.38$ minutes. $(p<0.01)$. Table 4 presents the results of a study of the level of physical development of the 7 th grade boys. Orenburg and Aktobe. The analysis of the obtained results allowed to determine the following patterns. By body weight, the Quetelet index of young men of Aktobe were ahead of schoolchildren of Orenburg (by $2.3 \mathrm{~kg}$ and $0.6 \mathrm{~kg} / \mathrm{m}^{2},<0.01$ ). The Erisman index was relatively higher among schoolchildren in Orenburg (by 0.03). For such indicators as body length, lung capacity, vital index, the strength of the right and left hands of the young men of Orenburg, the results were relatively higher than their peers from Aktobe. Thus, the length of the body is $-2.3 \mathrm{~cm}$, according to the $V C$ by $0.1 \mathrm{I}(\mathrm{p}<0.01)$, the vital index by $2.2(p<0.01)$, the strength of the right hand by $2.3 \mathrm{~kg}(p<0.01)$, the strength of the left hand - by 1.9 $\mathrm{kg}$. Heart rate was higher among schoolchildren of Aktobe (2.54 beats per minute), and systolic and diastolic blood pressure was higher among schoolchildren of Orenburg $(1.4$ and $0.2 \mathrm{mmHg}$ respectively, $p<0.01$ and $p>0.05$ ). Table 5 presents the indicators of the physical development of girls in the 7th grade of Orenburg and Aktobe. According to the length of the body, the Erisman Index, lung capacity, the vital index, the strength of the right and left hands, the results of schoolgirls in Orenburg were relatively higher than those of peers from Aktobe. Thus, the length of the body $-2.9 \mathrm{~cm}$, the Erisman index - on. 
Table 4. Indicators of physical development of boys 7 classes of Orenburg and Aktobe.

\begin{tabular}{|c|c|c|c|c|c|c|c|c|c|c|}
\hline \multirow{2}{*}{ No } & \multirow{2}{*}{ Indicators } & \multicolumn{3}{|c|}{$\begin{array}{c}\text { Orenburg } \\
n=100\end{array}$} & \multicolumn{3}{|c|}{$\begin{array}{l}\text { Aktobe } \\
n=100\end{array}$} & \multirow{2}{*}{ Growth } & \multirow[t]{2}{*}{$t$} & \multirow[t]{2}{*}{$p$} \\
\hline & & $\overline{\mathrm{X}}$ & $S$ & $\mathrm{~m}$ & $\bar{X}$ & $S$ & $\mathrm{~m}$ & & & \\
\hline 1 & Body length, cm & 162,4 & 2,29 & 0,32 & 160,1 & 1,62 & 0,2 & 1,7 & 7,18 & $<0,01$ \\
\hline 2 & Body weight, kg & 51,9 & 1,78 & 0,25 & 52,1 & 1,33 & 0,19 & 0,3 & 0,64 & $>0,05$ \\
\hline 3 & $\begin{array}{l}\text { Quetelet index, } \\
\mathrm{kg} / \mathrm{m}^{2}\end{array}$ & 19,7 & 0,62 & 0,09 & 20,3 & 0,71 & 0,10 & 3,0 & 4,62 & $<0,01$ \\
\hline 4 & Erisman index & 1,02 & 0,06 & 0,008 & 0,99 & 0,06 & 0,008 & 3,0 & 3 & $<0,01$ \\
\hline 5 & $\begin{array}{l}\text { Vital lung } \\
\text { capacity, I }\end{array}$ & 2,55 & 0,06 & 0,08 & 2,45 & 0,04 & 0,006 & 4,1 & 10 & $<0,01$ \\
\hline 6 & Life index & 49,8 & 0,62 & 0,09 & 47,6 & 0,8 & 0,11 & 4,6 & 15,7 & $<0,01$ \\
\hline 7 & $\begin{array}{l}\text { Strength of the } \\
\text { right hand, } \mathrm{kg}\end{array}$ & 22,8 & 0,64 & 0,09 & 20,5 & 0,73 & 0,10 & 11,2 & 17,6 & $<0,01$ \\
\hline 8 & $\begin{array}{l}\text { Strength of the } \\
\text { left hand, } \mathrm{kg}\end{array}$ & 21,8 & 0,71 & 0,10 & 19,9 & 0,82 & 0,12 & 9,5 & 11,8 & $<0,01$ \\
\hline 9 & $\begin{array}{c}\text { Heart rate cuts } \\
\text { beats / min }\end{array}$ & 73,06 & 0,61 & 0,09 & 75,6 & 0,91 & 0,13 & 3,4 & 15,8 & $<0,01$ \\
\hline 10 & $\begin{array}{c}\text { Arterial systolic } \\
\text { pressure, } \mathrm{mm} \mathrm{Hg}\end{array}$ & 120 & 1,04 & 0,15 & 118,6 & 1,17 & 0,17 & 1,2 & 6,1 & $<0,01$ \\
\hline 11 & $\begin{array}{l}\text { Arterial diastolic } \\
\text { pressure, } \mathrm{mm} \mathrm{Hg}\end{array}$ & 80 & 0,82 & 0,12 & 79,8 & 0,84 & 0,11 & 0,2 & 1,25 & $>0,05$ \\
\hline
\end{tabular}

The point 0.03 , the lung capacity is $0.11 \mathrm{I}$, the vital index is 1.9 , the strength of the right hand is $0.6 \mathrm{~kg}$, and the strength of the left hand is $0.9 \mathrm{~kg}$. By body weight $(0.7 \mathrm{~kg})$, Quetelet index $(0.9)$, heart rate $(1.08$ beats $/ \mathrm{min}$ ), arterial systolic ( $5 \mathrm{~mm} \mathrm{Hg}$ ) and diastolic $(2 \mathrm{~mm} \mathrm{Hg}$ ) pressure results of schoolchildren of Aktobe were relatively higher $(p<0.01)$.Table 6 presents the comparative data of the physical development indicators of schoolchildren of the 7th grades of 2019 and 1990. The data for 1990 are taken from a source (Bogatyrev,1998).

Table 5. Indicators of physical development of girls of 7 classes of Orenburg and Aktobe.

\begin{tabular}{|c|c|c|c|c|c|c|c|c|c|c|}
\hline \multirow{2}{*}{ No } & \multirow{2}{*}{ Indicators } & \multicolumn{3}{|c|}{ Orenburg } & \multicolumn{3}{c|}{ Aktobe } & \multirow{2}{*}{ Growth } & \multirow{2}{*}{$\mathrm{t}$} & \multirow{2}{*}{$\mathrm{p}$} \\
\cline { 3 - 11 } & & $\overline{\mathrm{X}}$ & $\mathrm{S}$ & $\mathrm{m}$ & $\overline{\mathrm{X}}$ & $\mathrm{S}$ & $\mathrm{m}$ & & & \\
\hline 1 & Body length, $\mathrm{cm}$ & 157,9 & 1,11 & 0,16 & 155 & 1,31 & 0,19 & 1,6 & 1,01 & $<0,01$ \\
\hline 2 & Body weight, $\mathrm{kg}$ & 50,9 & 0,71 & 0,1 & 51,6 & 0,73 & 0,1 & 1,3 & 5 & $<0,01$ \\
\hline 3 & $\begin{array}{c}\text { Quetelet index } \\
\text { kg/m }\end{array}$ & 20,6 & 0,63 & 0,09 & 21,5 & 0,78 & 0,11 & 4,3 & 6,42 & $<0,01$ \\
\hline 4 & Erisman index & 0,62 & 0,03 & 0,004 & 0,59 & 0,05 & 0,007 & 1,78 & 3,75 & $<0,01$ \\
\hline 5 & Vital lung capacity, I & 2,1 & 0,26 & 0,05 & 1,99 & 0,34 & 0,05 & 0,06 & 1,57 & $>0,05$ \\
\hline 6 & Life index & 42 & 0,49 & 0,070 & 40,1 & 0,47 & 0,66 & 4,7 & 1,97 & $>0,05$ \\
\hline 7 & $\begin{array}{c}\text { Strength of the right } \\
\text { hand, } \mathrm{kg}\end{array}$ & 19,5 & 0,6 & 0,08 & 18,9 & 0,78 & 0,11 & 3,1 & 4,29 & $<0,01$ \\
\hline 8 & $\begin{array}{c}\text { Strength of the left } \\
\text { hand, } \mathrm{kg}\end{array}$ & 17,8 & 0,71 & 0,10 & 16,9 & 0,86 & 0,12 & 5,3 & 5,6 & $<0,01$ \\
\hline 9 & Heart rate cuts & 88,32 & 1,05 & 0,15 & 89,42 & 0,89 & 0,12 & 1,2 & 5,8 & $<0,01$ \\
\hline \hline
\end{tabular}




\begin{tabular}{|c|c|c|c|c|c|c|c|c|c|c|}
\hline & beats / min & & & & & & & & & \\
\hline 10 & $\begin{array}{c}\text { Arterial systolic } \\
\text { pressure, } \mathrm{mm} \mathrm{Hg}\end{array}$ & 110 & 1,2 & 0,17 & 115 & 1,04 & 0,15 & 4,5 & 21,7 & $<0,01$ \\
\hline 11 & $\begin{array}{c}\text { Arterial diastolic } \\
\text { pressure, } \mathrm{mm} \mathrm{Hg}\end{array}$ & 80 & 0,88 & 0,012 & 82 & 0,67 & 0,09 & 2,5 & 22,2 & $<0,01$ \\
\hline
\end{tabular}

Table 6. Comparative data of the physical development indicators of schoolchildren of the 7th grades of 2019 and 1990.

\begin{tabular}{|c|c|c|c|}
\hline \multirow{2}{*}{ No } & \multirow{2}{*}{ Indicators } & \multicolumn{2}{|c|}{ Years } \\
\cline { 3 - 4 } & Body length, $\mathrm{cm}$ & 2019 & 1990 \\
\hline 1 & Body weight, $\mathrm{kg}$ & 160,1 & 155,8 \\
\hline 2 & Vital lung capacity, I & 52,1 & 52,7 \\
\hline 3 & 2,45 & 2,36 \\
\hline
\end{tabular}

As can be seen from table 6, the indicators of physical development of schoolchildren of the 7th grades of 2019 were relatively higher than in 1990 according to the length of the body and the vital capacity of the lungs (by $4.3 \mathrm{~cm}$ and 0.09 I, respectively). Only in terms of body mass, was it exceeded in school 7 th grade 1990 students (by $0.6 \mathrm{~kg}$ ). Thus, the analysis of the obtained results on the study of the level of physical fitness and physical development of schoolchildren of Orenburg and Aktobe revealed the following basic patterns. The lag of schoolchildren in Aktobe was observed in terms of physical fitness and physical development, such as: $60 \mathrm{~m}$ race (speed), 1,000m race (endurance), cross-beam traction (power), and long jump from the take-off run (speed power qualities), cross-country skiing (2 km, endurance), Erisman index, vital index, strength of hands, blood pressure. Along with this, we have identified relatively elevated values of body length and vital capacity of light 7th grade schoolchildren of 2019 compared with their peers of the 1990s. By body weight, a relative excess of the value was found in 1990 schoolchildren. Based on the results of solving the first and second problems of our research, we propose ways to optimize the physical training of schoolchildren.

1. In classes to distribute students according to their physical fitness and physical development.

2. Conducting classes in interesting sports. For those belonging to a special medical group - providing in a sparing mode of outdoor games, exercise with a metered load.

3. Development of work programs with the inclusion of physical exercises for the development of lagging physical qualities of schoolchildren (strength, speed, and endurance), exercises for the respiratory muscles.

4. Carrying out activities with parents to include them in the work on the physical education of their children (physical education and recreational activities "Dad, Mom and I are a sport family", "Health Day", etc., seminars on the themes of "healthy lifestyle", "family physical education ").

5. Introduction to the school practice of "exercise book on physical culture" to control students of their data on physical fitness and physical development. Inclusion in the school rating of a teacher of physical culture to increase his motivation and material interest.

\section{DISCUSSION}

The article obtained the following results. In the $60 \mathrm{~m}$ race, the young men of Orenburg were ahead of their peers from the city of Aktobe. The same tendency was noted in the long jump. But in the $1000 \mathrm{~m}$ race and throwing the ball, the young men of Aktobe showed relatively better results compared to schoolchildren from Orenburg. The length of the body is $2.3 \mathrm{~cm}$, according to the VCL by $0.1 \mathrm{I}(\mathrm{p}<0.01)$, the vital index by 2.2 ( $p$ 
$<0.01)$, the strength of the right hand by $2.3 \mathrm{~kg}(\mathrm{p}<0.01)$, by the strength of the left hand - by $1.9 \mathrm{~kg}$ of the young man of Orenburg were ahead of their peers from Aktobe. Comparison with the data obtained in earlier studies suggests that such studies with schoolchildren were conducted by (Makarova,2001), which revealed that "... teleuts boys and girls have lower indices of body length, leg length compared with Russian schoolchildren; the body of boys and girls of Teleuts reliably surpasses the peers of the Russian nationality in terms of overall aerobic endurance and coordination". Our studies coincide in terms of body length, where Kazakh schoolchildren lag behind the Russians from their followers. Also, in the $1000 \mathrm{~m}$ (endurance) race, Kazakh schoolchildren outnumbered the Russians from their peers. One of the results of our work was that among the factors determining the level of physical fitness and physical development of schoolchildren, teachers identified the material base, the lack of organization of special medical groups, the inconsistency of physical development with the passport age, the inappropriate development of independent work programs, homework to improve the physical fitness of schoolchildren, low motivation and indifference of parents. Comparison with the data obtained in earlier studies allows us to conclude that such studies with schoolchildren were conducted by (Zheleznyak \&Pyzyr' ,2002), who found that "the main factors that have a negative impact on the effectiveness of physical education in educational institutions Moscow, are: lack of material and technical support of the educational process, monitoring and analysis of the health of students; the discrepancy between the content of educational material and the characteristics of the students; low involvement of children and students in physical training classes; chronic deficiency of motor activity, low efficiency of management of physical education ". The difference in our study is that among the factors we identified that determine the level of physical development and physical fitness of schoolchildren, we also identified such as disorganization of special medical groups, inconsistency between physical development and passport age, improper development of independent work programs, and homework to improve physical fitness of schoolchildren. Also, in our work it was revealed that the indicators of physical development of schoolchildren of the 7th grades of 2019 were relatively higher than in 1990 along the length of the body and the vital capacity of the lungs (by $4.3 \mathrm{~cm}$ and 0.09 I respectively). Only in terms of body mass, was it exceeded in school 7 th grade 1990 students (by $0.6 \mathrm{~kg}$ ). Comparison with data obtained in earlier studies suggests that such studies with students were conducted by (Zhi et al, 2015), which revealed that "... the levels of height, weight, body mass index and chest circumference were clearly increased in 2010 compared with these levels in 1985, especially in the age group 9-13 years. ". The results of our research are generally the same, but the difference is that among the indicators noted by these authors, we studied the vital capacity of the lungs.

\section{CONCLUSION}

1. According to the teachers of physical culture of Orenburg and Aktobe, the factors determining the level of physical development and physical fitness of schoolchildren are the following: the material base, the small organization of special medical groups, the incompatibility of the physical development with the passport age, the undeveloped work programs, homework, contributing to physical fitness, not enough adequate content of the current program in physical culture, low motivation of schoolchildren and indifference of parents.

2. The lag of schoolchildren of Aktobe from peers from Orenburg on the development of speed $(60 \mathrm{~m}$ run), speed-power (long jump from the run), endurance (1,000 m run, ski run $2 \mathrm{~km}$ ), body length, vital index, blood pressure.

3. Developed recommendations on the distribution of students at the levels of physical fitness and physical development; conducting classes for them in sports; development of work programs by teachers with the inclusion of exercises to increase the level of physical fitness, respiratory muscles; carrying out activities with parents; the introduction of "exercise book on physical culture." 
The importance of the results obtained is due to the introduction of relatively new data on the levels of physical fitness and physical development of schoolchildren in Russian and Kazakhstan cities.

The theoretical significance of the results of the study is to complement the existing world knowledge about the physical fitness and physical development of schoolchildren, namely the directions and content of the study of this problem. The practical significance of the results of the work done is connected with the possibility of applying the results on the indicators of physical fitness, physical development of schoolchildren, their determining factors, in the world practice of physical culture specialists working with school contingents.

\section{REFERENCES}

Abdullah, A.G. \& Nandiyanto, AB.D. (2017). 1st annual applied science and engineering conference (AASEC), in conjunction with the international conference on sport science, health, and physical education (ICSSHPE): IOP Conference Series-Materials Science and Engineering. Issue 180. https://doi.org/10.1088/1757-899x/180/1/011001

Benite-Ribeiro, S.A., da Silva, V.V., Lima, K.L.L . \& dos Santos, J.M. (2016). Association between blood pressure, body mass index, eating habits, and physical activity in adolescents. Scientia medica, no 4(26). https://doi.org/10.15448/1980-6108.2016.4.24243

Bogatyrev, T.A. (1998). Reforming the regional system of physical education students. Almaty: Gylym.

Bortsova, A.N. (2006). Differential physical education of schoolgirls on the basis of taking into account the features of integral indicators of their physical condition. Volgograd.

Burlykov, V.D. (2006). Methods of physical education of schoolchildren of the Republic of Kalmykia on the basis of monitoring their physical development and physical fitness. Volgograd.

Delgado-Floody, P., Caamano-Navarrete, F., Palomino-Devia, C., Jerez-Mayorga, D. \& MartinezSalazar, C. (2019). Relationship in obese Chilean schoolchildren between physical fitness, physical activity levels and cardiovascular risk factors. Nutricion hospitalaria, no 1(36). 13-19. https://doi.org/10.20960/nh.1932

Dolzhikova, T.A. (2011). Differential physical education of middle school students of secondary schools with different levels of physical fitness. Krasnodar.

Feoktistov, M.F. (2010). Technology of development of physical abilities of adolescents based on sensitive periods. Volgograd.

Feresin, C., \& Močinić, S. (2017). Do we need to train teachers and students to care about other living beings? Humanities \& Social Sciences Reviews, 5(1), 33-45. https://doi.org/10.18510/hssr.2017.513

Gorobiy, A.Yu. (2007). Management of physical preparedness of high school students of secondary schools. St. Petersburg.

Greier, K. \& Drenowatz, C. (2018). Bidirectional association between weight status and motor skills in adolescents. A 4-year longitudinal study. Wiener klinische wochenschrift, no 9-10(130). 314-320. https://doi.org/10.1007/s00508-017-1311-y

Gu, X.L., Thomas, K.T. \& Chen, Y.L. (2017). The Role of Perceived and Actual Motor Competency on Children's Physical Activity and Cardiorespiratory Fitness during Middle Childhood. Journal of teaching in physical education, no 4(36). 388-397. https://doi.org/10.1123/itpe.2016-0192

Haynes, W., Waddington, G. \& Adams, R. (2017). Physical activity, academic and developmental measures in older primary school-children: A principal components analysis. Cogent psychology, no 1(4). https://doi.org/10.1080/23311908.2017.1413928

Kainov, A.N. (2004). Differential assessment of physical fitness of schoolchildren. Volgograd. 
Kall, L.B., Malmgren, H., Olsson, E., Linden, T. \& Nilsson, M. (2015). Effects of a Curricular Physical Activity Intervention on Children's School Performance, Wellness, and Brain Development. Journal of school health, no 10(85). 704-713. https://doi.org/10.1111/josh.12303

Kuraleva, 0.0. (2004). Individualization of physical fitness of children of primary school age based on constitutional identification. Astrakhan.

Landa, B.H. (2006). Methods of integrated assessment of physical development and physical fitness. Moscow: Sovetskiy sport.

Lebed', M.V. (1997). Features of physical fitness of schoolchildren living in the industrial pollution zone. Moscow.

Levushkin, S.P. (2005). Physiological rationale for the physical training of schoolchildren 7-17 years old with different body types. Moscow.

Luo, Q., Yang, L., Zhang, S., Su, J. \& Hao, D.M. (2018). Monitoring and evaluation of sports load for primary and middle school students. Journal of Mechanics in Medicine and Biology, no 8(18). https://doi.org/10.1142/S0219519418400286

Makarova, L.N. (2001). Study of the physical condition and prediction of physical abilities of schoolchildren of the Altai-Sayan Turks: On the example of the Teleut ethnic group. Omsk.

Marques, A., Santos, D.A., Hillman, C.H. \& Sardinha, L.B. (2018). How does academic achievement relate to cardiorespiratory fitness, self-reported physical activity and objectively reported physical activity: a systematic review in children and adolescents aged 6-18 years. British Journal of Sports Medicine, no 16(52). 1039. https://doi.org/10.1136/bjsports-2016-097361

Mooses, K., Pihu, M., Riso, E.M., Hannus, A., Kaasik, P. \& Kull, M. (2017). Physical Education Increases Daily Moderate to Vigorous Physical Activity and Reduces Sedentary Time. Journal of school health, no 8(87). 602-607. https://doi.org/10.1111/josh.12530

Novikasari, I. (2017). Factors Affecting the Development of Mathematical Knowledge for Teaching and Mathematical Beliefs of Prospective Primary Teachers. International Electronic Journal of Mathematics Education, 12(3), 243-264.

Puzyr', Yu.P. (2006). Management of physical education in educational institutions based on monitoring of physical condition. Moscow.

Santana, C.C.A., Azevedo, L.B., Cattuzzo, M.T., Hill, J.O., Andrade, L.P. \& Prado, W.L. (2017). Physical fitness and academic performance in youth: A systematic review. Scandinavian Journal of Medicine \& Science in Sports, no 6(27). 579-603. https://doi.org/10.1111/sms.12773

Schetinina, S. Yu. (2014). Physical education of schoolchildren in an integrated educational physical culture and sports environment. Scientific notes of the University. P.F. Lesgaft, no 10 (116). 150 158.

Zeighami, N., \& Bahmaei, R. (2016). Sociological study of structural and capital factors affecting the healthoriented lifestyle of over 15 year old citizens in Shiraz. UCT Journal of Social Sciences and Humanities Research, 4(3), 5-15.

Zhang, T., Thomas, K. \& Weiller, K. (2015). Predicting Physical Activity in 10-12 Year Old Children: A Social Ecological Approach. Journal of teaching in physical education, no 3(34). 517-536. https://doi.org/10.1123/itpe.2013-0195

Zhi, X.Y., Xi, W., Gao, L., Huang, J.P., Yang, X., Dai, W., Deng, Y.M. \& Zhang, X. (2015). Physical fitness status of children and adolescents in Tianjin of China during past three decades: a cross-sectional study. International journal of clinical and experimental medicine, no 6(8).

Zheleznyak, Yu.D. \& Petrov, P.K. (2002). Fundamentals of scientific and methodological activities in physical culture and sports. Moscow: Academiya. 


\section{(c) $(1) \Theta(9)$}

This work is licensed under a Attribution-NonCommercial-NoDerivatives 4.0 International (CC BY-NC-ND 4.0). 